\title{
Aging, Fatigue and Durability of Rubber Vibration Isolation Elements
}

\author{
Svetlana Polukoshko ${ }^{1}$, Andris Martinovs ${ }^{2}$, Svetlana Sokolova ${ }^{3}$ \\ ${ }^{1}$ Ventspils University College, Engineering Research Institute "VSRC”, Latvia, ${ }^{2}$ Rezekne Academy of \\ Technologies, Latvia, ${ }^{3}$ Riga Technical University, Institute of mechanics, Latvia
}

\begin{abstract}
This paper deal with shock and vibration insulators, which usually are performed from the elastomeric (rubber-like) materials. Elastomeric materials give many engineering advantages due to their capability of absorbing input energy much better than engineering materials, high elasticity, good dynamic properties, low volume compressibility, a linear relationship between stress and strain up to strain of $15 \% \div 20 \%$, resistance to aggressive environmental factors. Elastomeric materials are widely used in machine building, shipbuilding, civil engineering, aviation and aerospace as compensation devices, vibration dampers, shock absorbers. Laminated elastomers, consisting of interleaved thin layers of elastomer and rigid reinforcing layers are also successfully used as bearing, joints, dampers, compensating devices, shock-absorbers. Such structures have many advantages: ability to endure high stress (>200 MPa), ease of maintenance, non- necessity for lubrication, vibration and noise reduction, ability to work in a very dirty, dusty, abrasive environment. The disadvantage of elastomeric material are aging, i.e. changing its properties over time. In this paper the influence of aging of elastomeric materials on the damping properties of shock absorbers is considered based on the mechanical models of elastomers - Maxwell and Burgers modes. Fatigue endurance, i.e. the ability to withstand mechanical actions for a long time is studied based on experiments on dynamic shear with laminated rubber-metal structures. The experiments show that such structures have a very high fatigue life - up to 100 million cycles.
\end{abstract}

Keywords: elastomers, shock and vibration protection, aging, Burgers model, Maxwell model, fatigue.

\section{INTRODUCTION}

At the present time the questions of preventing the harmful effects of vibration and impacts on machines and construction elements require particular attention. In most cases it is necessary to provide of shock and vibration protection devices at the design stage. Elastomers, i. e. rubber and rubber-like materials, are most suitable material for shock absorbers and antivibration devices due to their capability of absorbing input energy much better than engineering materials. These materials have a specifical properties: high elasticity, resistance to aggressive environmental factors, good dynamic properties, low volume compressibility, a linear relationship between stress and strain up to strain of $15 \% \div 20 \%$. They are widely used in machine building, shipbuilding, civil engineering, aviation and aerospace as compensation devices, vibration dampers, shock absorbers [1] - [4].

Reinforced elastomers consist of alternating thin layers of elastomer and reinforcing layers of much more rigid material (usually metal), connected by means of vulcanization or gluing; number of elastomeric layers may be different, at least three. Reinforced elastomeric structures are able to endure high stress (>200 MPa) and they have many evident advantages: ease of maintenance, no necessity for lubrication, vibration and noise reduction, ability to work in a very dirty, dusty, abrasive environment, improving the dynamics of machines which provide

the properties of rubber and lack of clearances, as well as compensation of various skew distortions and inaccuracies in joint connection; smaller size, weight and cost [5] - [7]. Packages of thin-layered rubbermetal elements (further TRME) are successfully used as bearing, joints, dampers, compensating devices, shock-absorbers etc. Examples of elastomeric shock absorbers and TRME packages are presented in Fig. 1 .

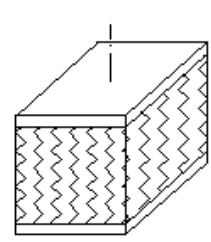

(a)

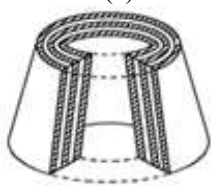

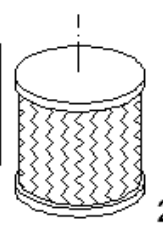

(b)

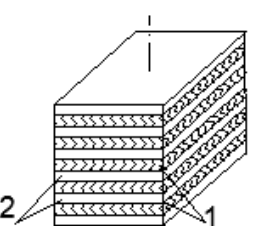

(c)

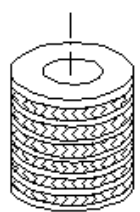

(d)

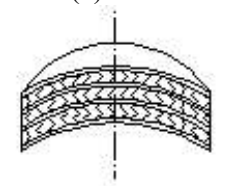

(f)

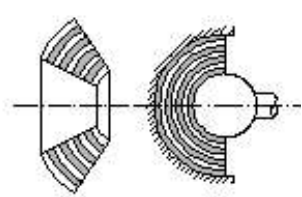

(g)

(f)
Fig. 1. Construction of typical elastomeric shock absorbers: (a) rectangular prism, (b) - straight circular cylinder; blocks of TRME elements: (c) - rectangular, (d) - cylindrical form, (e) - conical form, (f) - spherical pad, (g) - spherical nozzle, (f) spherical hinge; 1 - rubber layer, 2 - metal layer.

Since many elastomeric and rubber-metal products, serving as elastic links, take up the impulsive load, 
alternating-sign load, periodical and non-periodical high-frequency load, it is necessary to study the behaviour and the mechanical properties of rubber under dynamic loads. The most important characteristic of the service performance of rubber devices operating under conditions of repeated cyclic loading (alternate stress) in couplings, hinges, etc., is the ability to withstand mechanical actions for a long time, that is, fatigue endurance. The simplest and most reliable comparison of the service life with alternating stresses is the evaluation of the selfheating temperature, i.e. each specific temperature of self-heating corresponds to a concise lifetime.

It is also necessary to take into account the aging of material - changing its properties with time. When considering aging, it is assumed that the parameters of the model slowly change their properties. In this paper, it is proposed to account for the aging of rubber by multiplying the constants of material in Maxwell and Buzgers models by special functions and time. To determine slow processes (creep and relaxation), the best is considered the four-element Burgers model.

\section{MATEARIALSS AND METHODS \\ A. Aging treatment of rubber-metal elements}

Aging of the material is its properties ochanging in time under the influence of air or aggressive media. The duration of this process is very large even in comparison with the relaxation time. Therefore, accounting of aging is usually performed by a substitution of the empirically determined functions of time instead of material constants. To determine the slow processes (creep and relaxation), the differential relationships are used, which provide coincidence with the experiment. The four-elements model of Burgers is considered the best (Fig.2) [8] [11].

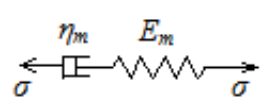

(a)

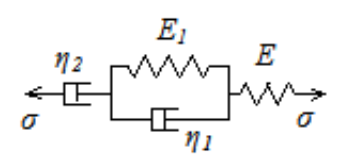

(b)
Fig. 2. Scheme of mechanical models of elastomers: (a) Maxwell model, (b) four-element Burgers model

For this model the relationship between stress and strain is expressed by the equation:

$\frac{1}{E} \ddot{\sigma}+\left(\frac{1}{\eta_{1}}+\frac{1}{\eta_{2}}+\frac{E_{1}}{E \eta_{1}}\right) \dot{\sigma}+\frac{E_{1}}{\eta_{1} \eta_{2}} \sigma=\ddot{\varepsilon}+\frac{E_{1}}{\eta_{1}} \dot{\varepsilon}$.

In the particular case if $\eta_{1}=\infty$ Burgers model is transforming into Maxwell model, which quite well describes the creep before destruction.

$$
\frac{\dot{\sigma}}{E_{m}}+\frac{\sigma}{\eta_{m}}=\dot{\varepsilon}
$$

When aging is taken into account in accordance with equations (1) or (2) it is assumed that the parameters $E, E_{1}, \eta_{1}, \eta_{2}$ change their properties very slowly. To generalize the results, taking into account the temperature changing, the dependencies are at once given in the reduced time.

$$
\begin{array}{r}
E\left(t_{n}\right)=E \varphi_{1}\left(t_{n}\right), \quad E_{1}\left(t_{n}\right)=E_{1} \varphi_{2}\left(t_{n}\right), \\
\eta_{1}\left(t_{n}\right)=\eta_{1} \varphi_{3}\left(t_{n}\right), \eta_{2}\left(t_{n}\right)=\eta_{2} \varphi_{4}\left(t_{n}\right)
\end{array}
$$

The experiment confirms the possibility of taking an approximation:

$$
\varphi_{i}\left(t_{n}\right)=1+A_{i} t_{n}
$$

For Maxwell model the relationships are

$$
\begin{aligned}
& \frac{E_{m}\left(t_{n}\right)}{E}=\varphi_{1 m}\left(t_{n}\right)=1+A_{m} t_{n} \\
& \frac{\eta_{m}\left(t_{n}\right)}{\eta}=\varphi_{2 m}\left(t_{n}\right)=1+B_{m} t_{n} .
\end{aligned}
$$

The value of Burgers model constants $E, E_{1}, \eta_{1}, \eta_{2}$ and corresponding them $A_{1}, A_{2}, A_{3}, A_{4}$ are estimated and tabularized for some kinds of rubbers, as well as value $E_{m}, \eta_{m}, A_{m}, B_{m}$ for Maxwell model [7].

To obtain creep under the condition $\sigma=\sigma_{0}=$ const assuming Maxwell model of rubber, if the stress is applied at time $\tau$, the strain at time $t$ is equal to:

$$
\begin{aligned}
& \varepsilon(t, \tau)=\sigma_{0}\left[\int_{\tau}^{t} \frac{d \tau}{R_{m}((\tau)}+\frac{1}{E_{m}(\tau)}\right]= \\
& =\sigma_{0}\left[\frac{1}{R_{m} B_{m}} \ln \left|\frac{1+B_{m} t}{1+B_{m} \tau}\right|+\frac{1}{E_{m}\left(1+A_{m} \tau\right)}\right] .
\end{aligned}
$$

A1. Thin- layered rubber-metal vibration isolator In order to trace how the age of rubber effect on the service properties of elastomeric devices we consider the damping properties of rubber shock absorber. This device serves occasionally for a short period of time, so the fatigue is not taken into account, for example, it may be seismic protector. In [12] the formulas are derived for the damping properties of vibroisolator under unilateral harmonic excitation (Fig.2).

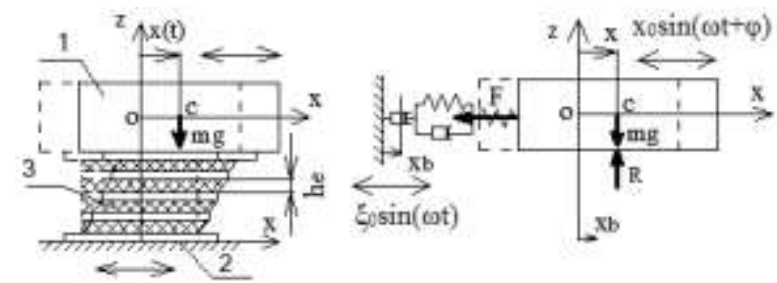

Fig. 3. Scheme of the object vibration with elastomeric shock absorber 1 - protected object, 2 - vibration base, 3 - vibroisolator

Damping properties are expressed by the ratio of amplitude of the driving vibration to the amplitude of the forced oscillations of object.

For Maxwell model of the elastomer we have [12]: 
Environment. Technology. Resources, Rezekne, Latvia Proceedings of the $11^{\text {th }}$ International Scientific and Practical Conference. Volume III, 269-275

$$
\frac{x_{0}}{\xi_{0}}(\omega)=\frac{\eta_{m} \omega_{0}^{2}}{\sqrt{E_{m}{ }^{2} \omega^{2}+\eta_{m}{ }^{2}\left(\omega^{2}-\omega_{0}^{2}\right)^{2}}},
$$

In case of aging taking into account equations (5):

$$
\begin{aligned}
& \frac{x_{a 0}}{\xi_{0}}(\omega)=\frac{\omega_{a 0}^{2}}{\sqrt{\frac{E_{m}{ }^{2}}{\eta_{m}} \frac{\left(1+A_{m} t_{n}\right)^{2}}{\left(1+B_{m} t_{n}\right)^{2}} \omega^{2}+\left(\omega^{2}-\omega_{a 0}^{2}\right)^{2}}}, \\
& \omega_{a 0}=\omega_{0} \sqrt{1+A_{m} t_{n}}
\end{aligned}
$$

For the case of resonance, i.e. $\omega=\omega_{0}$ without aging and with aging $\omega=\omega_{a 0}$ from (7) and (8) it is obtained:

$$
\frac{x_{0}}{\xi_{0}}(\omega)=\frac{\eta_{m}}{E_{m}} \omega, \quad \frac{x_{a 0}}{\xi_{0}}(\omega)=\frac{\eta_{m}\left(1+B_{m} t_{n}\right)}{E_{m}\left(1+A_{m} t_{n}\right)} \omega .
$$

For Burgers model of elastomer $\mathrm{x}_{0} / \xi_{\theta}$ ratio received in [12] is equal:

$$
\begin{aligned}
& \frac{x_{0}}{\xi_{0}}(\omega)=\frac{\omega_{0}^{2}}{\omega \eta_{1}} \sqrt{E_{1}{ }^{2}+\eta_{1}{ }^{2} \omega^{2}} . \\
& \cdot\left\{\begin{array}{l}
{\left[\left(\omega^{2}-\omega_{0}{ }^{2}\right)-\frac{E_{1} E}{\eta_{1} \eta_{2}}\right]^{2}+} \\
+\omega^{2}\left[\frac{E_{1} \omega_{0}^{2}}{\eta_{1} \omega^{2}}-\left(\frac{E}{\eta_{2}}+\frac{E+E_{1}}{\eta_{1}}\right)\right]^{2}
\end{array}\right\}^{-\frac{1}{2}} .
\end{aligned}
$$

For the case of resonance if $\omega=\omega_{0}$ from (10) it is received:

$$
\frac{x_{0}}{\xi_{0}}(\omega)=\frac{\omega \eta_{2} \sqrt{E_{1}^{2}+\eta_{1}^{2} \omega^{2}}}{E \sqrt{E_{1}^{2}+\left(\eta_{1}+\eta_{2}\right)^{2} \omega^{2}}} .
$$

In order to take into account aging it is necessary to substitute into the equations (10) and (11) instead of constants $E, E_{1}, \eta_{1}, \eta_{2}$ expressions $E(t), E_{l}(t), \eta_{1}(t)$, $\eta_{2}(t)$ in accordance with (3) and (4) and $\omega_{a 0}$ instead of $\omega_{0}$. Since $E$ is considered as initial modulus in Burgers model natural frequencies $\omega_{0}$ and $\omega_{a 0}$ are assumed:

$$
\omega_{0}=\sqrt{A E / m h}, \omega_{a 0}=\omega_{0} \sqrt{1+A_{1} t_{n}} .
$$

A2. Impact rigid body with rubber shock absorber

In this part the influence of aging on the restitution coefficient of rubber shock absorber is studied in case of direct central impact (Fig.4).

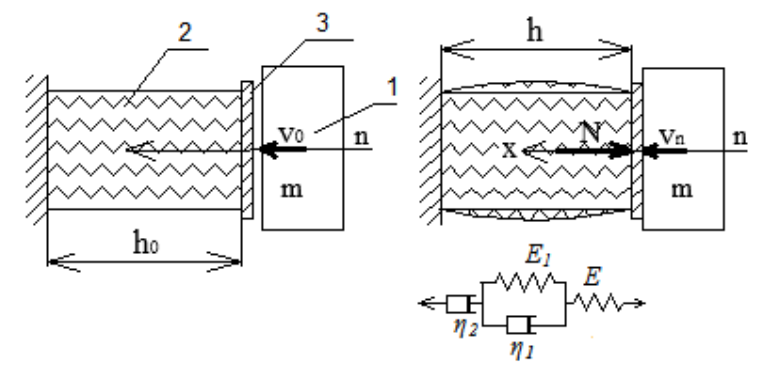

Fig. 4. Scheme of rubber shock absorber: 1-impact body, $2-$ rubber cylinder, 3 - reinforcing plate

After collision of body and rubber shock absorber they move together in $x$-direction till the velocity reaches zero value and then move in opposite direction till disconnection. Mass and deformation of reinforcing plate 3 are not taken into account. The equation of body motion during impact:

$m \ddot{x}=-N=-\sigma A, x=\varepsilon h=\varepsilon\left(h_{0}-x\right)$,

where A - cross-section area of absorber.

Substituting equations (12) and corresponding derivatives from (12) into equation (1) it is obtained:

$$
\begin{aligned}
& \dddot{x}+\left(\frac{E}{\eta_{2}}+\frac{E+E_{1}}{\eta_{1}}\right) \ddot{x}+\left(\frac{E_{1} E}{\eta_{1} \eta_{2}}+\frac{E A}{m\left(h_{0}-x\right)}\right) \dot{x}+ \\
& +\frac{E_{1}}{\eta_{1}} \frac{E A}{m\left(h_{0}-x\right)} x=0
\end{aligned}
$$

Equation (13) is solved numerically under initial conditions: if $t=0, x=0 v=v_{0}, w_{0}=0$.

\section{B. Fatigue and durability of TRME elements}

The most important characteristic of TRME performance qualities, operating under conditions of repeated cyclic shear loading with simultaneous permanent action of the static load in the constructions of couplings, hinges, etc. is the ability to withstand mechanical influences for a long time, i.e. fatigue life.

Analysis of numerous experimental data shows that the frequency of dynamic loading for rubber, which varies in a not too wide range of practically realizable frequencies $(10-100 \mathrm{~Hz}$ ), does not (or has very little effect) on fatigue life at a constant temperature.

The testing of TRME was carried out at Moscow Scientific Research Institute VNIINMASH; when carrying out tests of TPME for fatigue life, only mechanical parameters were taken into account as variable parameters, all other test conditions (temperature, environmental composition) were considered as unchanged. TRME with flat layers (dimensions are given in Table I) were tested during the operation of the compensating coupling, the construction of which is shown in Fig. 5 [13].

The coupling consists of two half-couplings 1 and 2 and a cross slide block 3 with thin-layered rubbermetal elements 4 fixed on it (two identical elements were attached to each side of the slide block). The width of the groove formed by the outstanding cams 5 and 6 of the half couplings is less than the thickness of the slide block, and the cam 6 is divided by a slot 7 into an elastic 8 with a threaded hole 11 and a rigid 9 part with a cylindrical hole 10 .

In these coaxial holes, a bolt 12 is installed during assembly, which, pressing the head into the rigid part 
of the cam, presses the elastic part and the cross slide block freely enters the groove.

After removing the bolt 12, the elastic part of the cam compresses the rubber-metal elements. Then the screws are inserted into the threaded elements, which, through the cam 6 and the gaskets, evenly increase the compression load of the TPME.

Table I

Testing elements dimension

\begin{tabular}{|c|c|c|c|c|}
\hline $\begin{array}{c}\text { Number } \\
\text { of } \\
\text { elements } \\
\text { No }\end{array}$ & $\begin{array}{c}\text { Thickness of } \\
\text { one layer of } \\
\text { rubber 8871, } \\
\mathrm{mm}\end{array}$ & $\begin{array}{c}\text { Number of } \\
\text { rubber } \\
\text { layers, } \mathrm{n} \\
\text { items }\end{array}$ & $\begin{array}{c}\text { Total thickness } \\
\text { of rubber } \\
\text { layers, } \\
\text { mm }\end{array}$ & $\begin{array}{c}\text { Thickness } \\
\text { of one } \\
\text { metal } \\
\text { layer, } \mathrm{mm}\end{array}$ \\
\hline $\mathbf{1}$ & 0.16 & 24 & 3.84 & 0.05 \\
\hline $\mathbf{2}$ & 033 & 13 & 4.29 & 0.05 \\
\hline $\mathbf{3}$ & 0.39 & 12 & 4.68 & 0.05 \\
\hline $\mathbf{4}$ & 0.25 & 8 & 2.00 & 0.05 \\
\hline $\mathbf{5}$ & 0.10 & 17 & 1.70 & 0.10 \\
\hline $\mathbf{6}$ & 0.28 & 13 & 3.64 & 0.10 \\
\hline $\mathbf{7}$ & 0.44 & 9 & .3 .96 & 0.10 \\
\hline
\end{tabular}
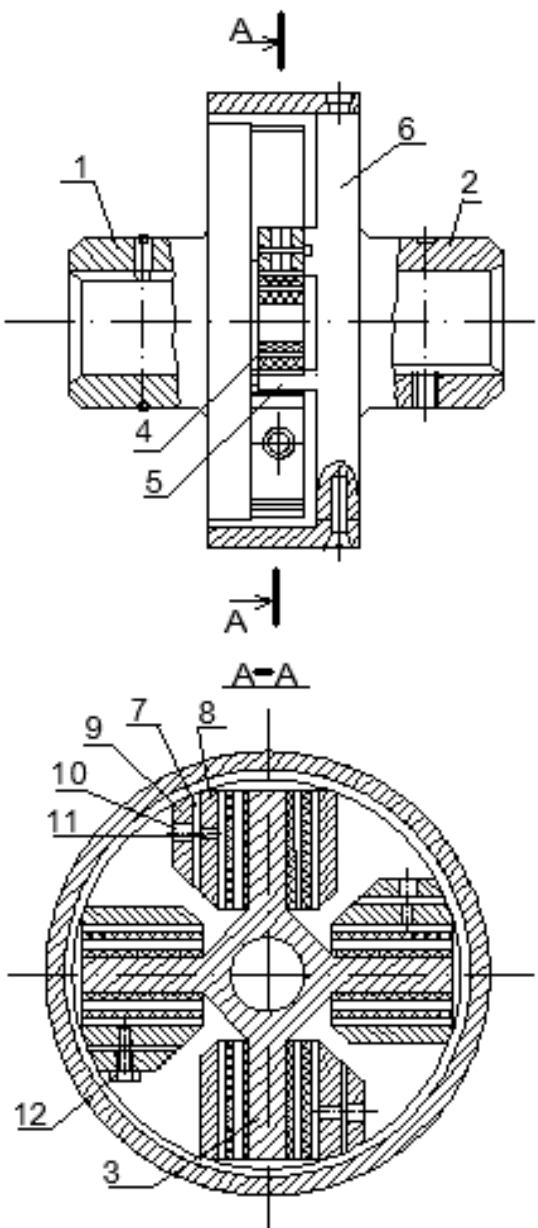

Fig. 5. Cross-rocker coupling: 1,2-half-coupling

The compression deformation was determined on an instrumental microscope after the final assembly of the coupling. The test showed that after the testing a strain remained unchanged in the range of $5-10 \%$. The compression force $\mathrm{Pz}$ was determined according to the compression deformation by the previously obtained calibration curves (for all elements the compression force is equal $9-10 \mathrm{kN}$ ). For an equal area of all elements $A=1.8 \mathrm{~cm}^{2}$, the specific pressure $p$ on the clutch cams is $50-55 \mathrm{MPa}$.
The coupling connected the drive shaft with the electric motor AO-42-4 ( $\mathrm{N}=2.8 \mathrm{~kW}, \mathrm{n}=1440 \mathrm{rpm})$ with a brake shaft that worked idly. Because of the radial misalignment between the two shafts e, artificially created with calibrated plates, placed under the feet of the electric motor, a shift of each rubber-metal element was created twice in one revolution or at a frequency of $50 \mathrm{~Hz}$. The observed decrease of shear modulus by $8-10 \%$ compared to the initial one was the criterion of fatigue life of TRME; this decreasing is explained by the fact that under the action of intensive variable stresses in the rubber, the action of chemical and physical-mechanical processes slowly destroying the rubber structure and fatigue failure of rubber can occur in TRME.

Stresses reduction (relaxation) is the most obvious manifestation of the process of fatigue. This process is related to relaxation under static deformation and creep under static loading. After each stage of testing (a certain number of cycles $N$ and the misalignment value $e$ ), the coupling was disassembled and the shear stiffness of the TRME was measured.

When the shear rigidity was reduced by not less than $8-10 \%$, the relative deformation of the cyclic shear $\gamma$ corresponding to a given number of cycles $N$ was noted (Fig. 5). In the next stage new elements, in all respects identical, participated. The sequence and conditions of the experiment fulfilling may be seen from Table II. Analysis of the dependence of the relative shear strain $\gamma$ on the number of cycles $N$ shows that the number of cycles characterizing the working capacity of the TRME decreases with increasing of relative shear deformation (Fig. 5). Throughout all experiments the destruction of TRME was not observed. Experimental curve may be approximated by exponential curve or by logarithmical curve, the best coincidence gives logarithmical approximation, presented in Fig. 3, where approximate function is:

$$
\gamma_{a}(N)=0.966-0.128 \ln (N-1.411)
$$


where $N$ - number of millions of cycles, $\gamma$ - relative shear deformation.

Using dependence (14) it is possible to calculate the allowed relative share strain for laminated bearing.

When carrying out the second stage of fatigue life tests, one previously destroyed (when cutting) element No. 6 with partially peeled rubber was installed in the coupling. However, this element worked normally during $20 \mathrm{mln}$ of cycles with a relative shear deformation $\gamma=0.274$ and $p=55 \mathrm{MPa}$, which proves the possibility of maintaining TRME operating capacity even under conditions of partial failure.

In whole, the experiment proved that TRMEs have a very high fatigue life (to 100 million cycles), which may be further improved when the manufacturing process will be improved.

Table II

Relative shear deformation under different CONDITIONS

\begin{tabular}{|c|c|c|c|c|c|c|}
\hline $\begin{array}{c}\text { Number } \\
\text { of } \\
\text { elements } \\
\text { No }\end{array}$ & \multicolumn{6}{|c|}{ Relative shear deformation $\gamma$ under different value of misalignment $e$ and number of } \\
\cline { 2 - 7 } & $\begin{array}{c}\mathrm{e}=0.5 \mathrm{~mm} \\
\mathrm{~N}=20 \mathrm{mln} .\end{array}$ & $\begin{array}{c}\mathrm{e}=1 \mathrm{~mm} \\
\mathrm{~N}=20 \mathrm{mln} .\end{array}$ & $\begin{array}{c}\mathrm{e}=2 \mathrm{~mm} \\
\mathrm{~N}=1.1 \mathrm{mln} .\end{array}$ & $\begin{array}{c}\mathrm{e}=2 \mathrm{~mm} \\
\mathrm{~N}-1.4 \mathrm{mln} .\end{array}$ & $\begin{array}{c}\mathrm{e}=2.5 \mathrm{~mm} \\
\mathrm{~N}=12 \mathrm{mln} .\end{array}$ & $\begin{array}{c}\mathrm{e}=0.4 \mathrm{~mm} \\
\mathrm{~N}=12 \mathrm{mln} .\end{array}$ \\
\hline $\mathbf{1}$ & 0.13 & 026 & 0.52 & - & - & - \\
\hline $\mathbf{2}$ & - & - & - & 0.47 & 0.58 & 0.435 \\
\hline $\mathbf{3}$ & - & - & - & 0.43 & 0.535 & 0.835 \\
\hline $\mathbf{4}$ & 0.25 & 0.5 & 1.0 & - & - & 1.1 \\
\hline $\mathbf{5}$ & 0.294 & 0.59 & 1.17 & - & - & - \\
\hline $\mathbf{6}$ & 0.137 & 0.274 & 0.55 & 0.55 & 0.686 & 1.1 \\
\hline $\mathbf{7}$ & - & - & - & 0.505 & 0.63 & 1.01 \\
\hline
\end{tabular}

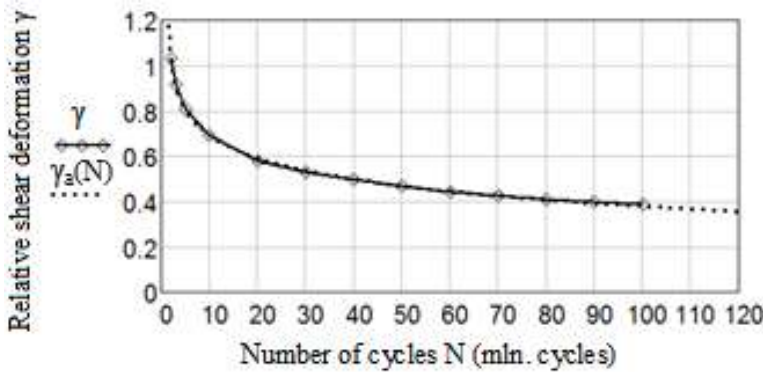

Fig. 5. Plot of dependence of the relative shear $\gamma$ deformation on the number of cycles $\mathrm{N}$ : $\bigodot_{-}$-experimental curve, $\cdots \cdots$ approximated curve.

\section{B 1. Definition of fatigue life}

The simplest and at the same time fairly reliable comparison of the service life with alternating stresses is the evaluation of the self-heating temperature. It means that each specific temperature of self-heating corresponds to a specific service life. For some grades of rubber these dependencies are tabulated [7].

The following dependence was experimentally established for the number of cycles $\mathrm{N}^{*}$ before failure:

$$
N^{*}=N(W, T)=\left(\frac{W_{P}}{W}\right)^{n},
$$

where $W p$ - a specific work of material destruction; $W$ - a specific potential energy; $n$ - coefficient.

Specific work of material destruction is defined as

$$
W_{P}=W_{1} e^{-W_{2} T},
$$

where $T$ is the operating temperature, ${ }^{\circ} \mathrm{C}, W_{1}$ and $W_{2}$ are tabular data.
For the rubber 8871 the values of coefficients in accordance with [7] are next: $W_{1}=46.4 \mathrm{MPa} \cdot \mathrm{m}^{3}$, $W_{2}=0.0261 \mathrm{deg}^{-1}, n=2.94$. Assuming the operating temperature $T=80{ }^{\circ} \mathrm{C}$, from (6) specific work of material failure is received $W_{p}=5.751 \mathrm{MNm}$.

$$
W=\frac{W_{P}}{\sqrt[n]{N^{*}}},
$$

Plot of dependence the specific potential energy on critical number of cycles is presented in Fig. 6.

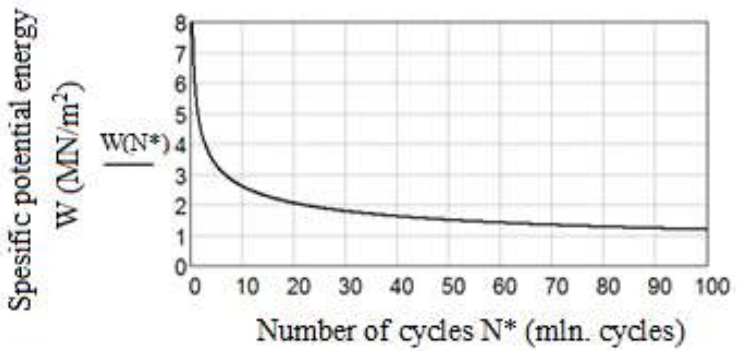

Fig. 6. Plot of dependence of specific potential energy on number of cycles before failure for rubber 8871 .

\section{RESULTS AND DISCUSSION}

For numerical examples the rubber of grade 8871 was chosen, necessary data were taken from [7]. The constants and the aging coefficients for Maxwell model have the values: $E_{m}=1.23 \mathrm{MPa}, \eta_{m}=1.16 \mathrm{MPa}$, $A_{m}=0.65 \cdot 10^{-4} \mathrm{day}^{-1}, B_{m}=3.16 \cdot 10^{-4} \mathrm{day}^{-1}$. The constants of four-elements Burgers model are: $E=1.63 \mathrm{MPa}$, $E_{l}=5.09 \mathrm{MPa}, \eta_{1}=36.3 \mathrm{MPa}, \eta_{2}=1.16 \mathrm{MPa}$, the aging coefficients: $A_{1}=0.81 \cdot 10^{-4}$ day $^{-1}, A_{2}=0.33 \cdot 10^{-4}$ day $^{-1}, A_{3}=-0.24 \cdot 10^{-4}$ day $^{-1}, A_{4}=3.16 \cdot 10^{-4}$ day $^{-1}$.

The results of investigation of aging influence on damping properties of multilayered rubber-metal vibroisolator, shown in Fig.3, are presented in Fig.78. In Fig. 7 the dependence of amplitude $\mathrm{x}_{0} / \xi_{\theta}$ ratio on exitation frequence $\omega$ is given in accordance with Maxwell model, in Fig. 8 - in accordance with Burgers model. Time of aging is assumed three years. 


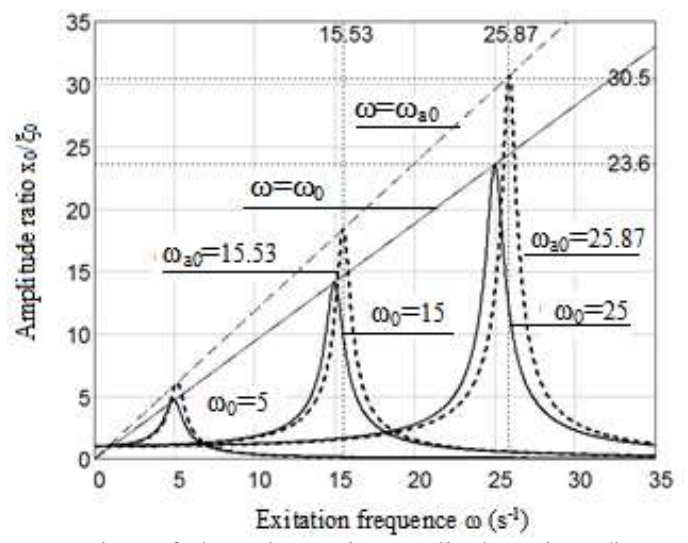

Fig. 7. Plots of dependence the amplitude ratio $\mathrm{x}_{0} / \xi_{0}$ on the excitation frequency $\omega$ for Maxwell model: — without aging, -..- taking into account aging 3 years.

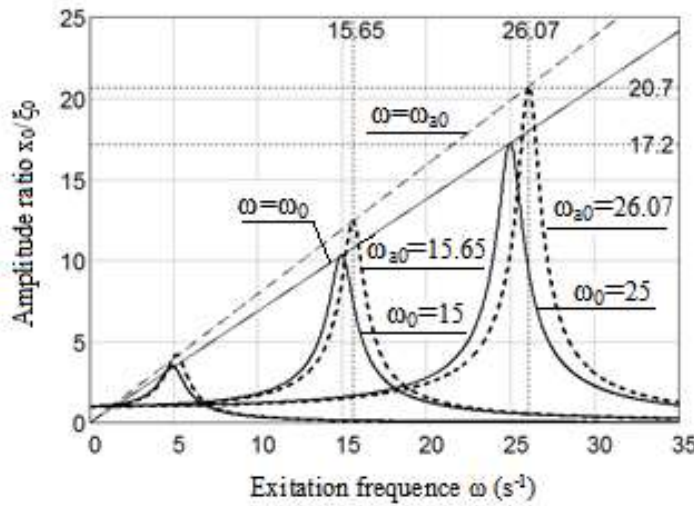

a) from $\omega=0 \mathrm{~s}^{-1}$ to $\omega=35 \mathrm{~s}^{-1}$

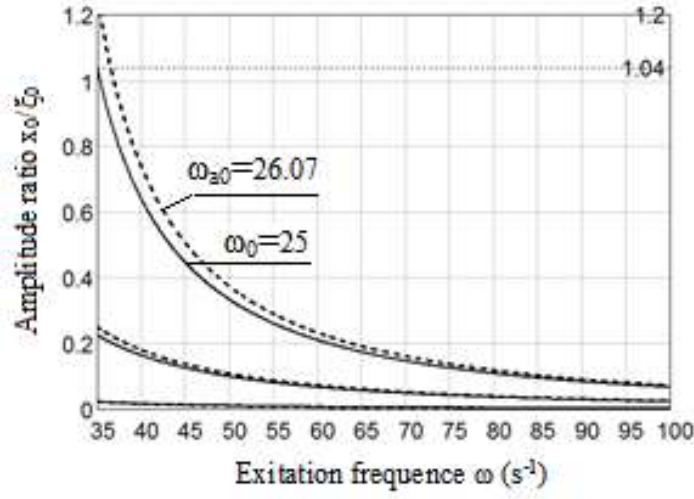

b) from $\omega=35 \mathrm{~s}^{-1}$ to $\omega=100 \mathrm{~s}^{-1}$

Fig. 8. Plots of dependence the amplitude ratio $x_{0} / \xi_{0}$ on excitation frequency $\omega$ for Burgers model: — without aging, -... taking into account aging 3 years.

For both models three natural frequencies is examined: $\omega_{0}=5,15,25 \mathrm{~s}^{-1}$ without aging, which increase natural frequency. Burgers model shows better damping properties in comparison with Maxwell; the difference appear near resonance zone, in post-resonance zone (hear $\omega>35 \mathrm{~s}^{-1}$ ) the results of both model are coincided.

For definition the aging influence on restitution coefficient (Fig. 4) body with mass $m=20 \mathrm{~kg}$, colliding rubber 8871 cylinder $d=0.06 \mathrm{~m} h=0.06 \mathrm{~m}$ with initial velocity $v_{0}=1 \mathrm{~m} / \mathrm{s}$, is considered. Post -impact velocity for this size of shock absorbers is shown in Fig. 9, 10.

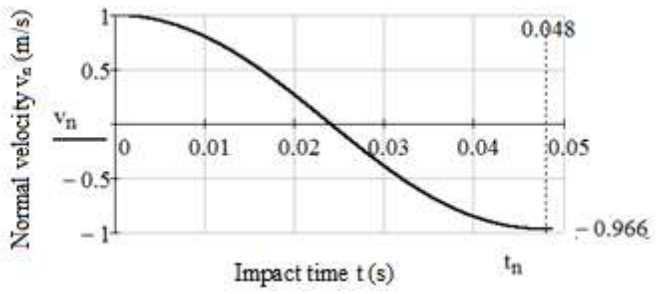

Fig. 9. Plot of dependence of impact velocity on time without aging

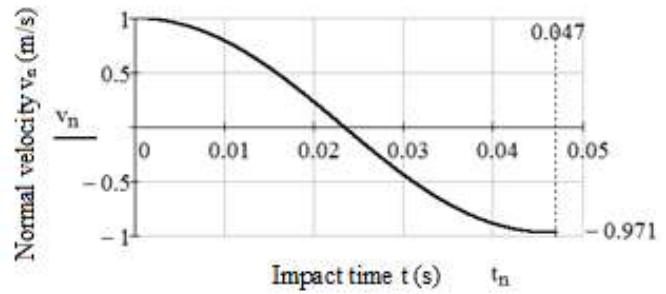

Fig. 6. Plot of dependence of impact velocity on time taking into account aging 3 years.

\section{CONCLUSIONS}

In this paper the influence of aging on the working properties of rubber-metal shock absorbers is discussed. The changing of damping properties depending on aging for two mechanical model of elastomeric material is studied. The aging influence on restitution coefficient during impact was defined using Burgers model of elastomer. Fatigue life definition in under shear stress was performed by series of experiments. These experiments proved that TRMEs have a very high fatigue life.

\section{REFERENCES}

[1] A. N. Gent, Engineering with Rubber: How to Design Rubber Components. Munich, Carl Hanser Verlag, 2011.

[2] W. L. Hinks, Randolph Research Co. (RRC). Laminatedrubber bearings: heavy duty composites for aerospace and undersea. Presentation at the Spring 2013 183rd Technical Meeting of the Rubber Division of the American Chemical Society. [Online]. Available on: http://randolphresearch.com/LAMINATED\%20Rubber\%20 Bearings\%20Rubber\%20Div\%20paper2_trim.htm

[3] J. T. Bauman, Fatigue, Stress and Strain of Rubber Components: Guide for Design Engineers. Munich, Carl Hanser Verlag, 2008

[4] J. M. Kelly and D. A. Konstantinidis, Mechanics of Rubber Bearings for Seismic and Vibration Isolation. UK: John Wiley \& Sons, 2011.

[5] D. A. Konstantinidis and J. M. Kelly, Advances in Low-Cost Seismic Isolation with Rubber. Proceedings of the 10th U.S. National Conference in Earthquake Engineering, July 2125, 2014, Earthquake Engineering Research Institute, Anchorage, Alaska, [Online]. Available on: https://www. nees.org/resources/11388/download/10NCEE-000422.pdf

[6] V. A. Lepetov, Rubber Technical Products. (Резинотехнические изделия). Moscow, Chemistry, 1972. (In Russian)

[7] V. T Lyapunov, E. E Lavendel and S. A Shlyapochnikov, Rubber vibration isolators: Habdbook, (Резиновые виброизоляторы: Справочник) Leningrad: Sudostrojenie, 1988. (In Russian)

[8] A. R. Bhuiyan; A. F. M. S. Amin; T. Hossain; and Y. Okui "Nonlinear viscosity law for rate-dependent response of high damping rubber: FE implementation and verification", in Constitutive Models for Rubber $V$ - Boukamel, 
Environment. Technology. Resources, Rezekne, Latvia Proceedings of the $11^{\text {th }}$ International Scientific and Practical Conference. Volume III, 269-275

Laiarinandrasana, Meo \& Verron (eds), Taylor \& Francis Group, London, 2008, pp. 279 - 284.

[9] V.N. Poturaev and V.I. Dyrda, Rubber Machine Elements. (Резиновые детали машин), Mashinostrojenie, Moscow, 1977. (in Russian)

[10] A. R. Bhuiyan Y. Okui , H. Mitamurab and T. A. Imaic, Rheology Model of High Damping Rubber Bearings for Seismic Analysis: Identification of nonlinear viscosity, International Journal of Solids and Structures. 46 (2009), 1778-1792, [Online]. Available on: http://www.sciencedirect.com/science/article/pii/S00207683 09000298

[11] A. A. Iljushin and B. E. Pobedrja, Fundamentals of mathematical theory thermo-viscoelasticity, (Основы математической теории термовязко-упругости), Nauka, Moscow, 1970.

[12] S. Polukoshko, "Estimation of damping capacity of rubber vibration izolators under harmonic exitation.", in "Vibroengineering Procedia", Ortober 2016, Volume 8,.pp. $50-56$

[13] N. S Gusyatinskaya, Application of Thin Layered RubberMetal Elements(TRME) in Machine-Tools and Other Engines (Применение тонкослойных резинометаллических элементов (ТРМЭ) в станках и других машинах). Mashinostroenie, Moscow, 1978. (In Russian). 